\section{Brown on Boranes}

Boranes in Organic Chemistry. By Herbert C. Brown. Pp. xiv +462 . (Cornell University: New York, August 1972.) $\$ 24.50$.

THIS book is part of a distinguished series in which eminent chemists have provided written records of their Baker Lectures at Cornell University. Professor Brown essentially gives a scientific autobiography. In this sense the title of the book is misleading in that the subject of organoboranes forms but one of six parts discussing various aspects of borane chemistry.

In part 1 the principal topics relate to diborane and borohydrides, and free radical substitution reactions. These two diverse topics commanded Professor Brown's interest because of the presence at the University of Chicago of H. I. Schlesinger and M. S. Karasch.

Part 2 is devoted to Brown's contribution to the assessment of the role of steric strains in chemistry. His work on donor-acceptor addition complexes of boron led him to the idea of these as models for saturated carbon compounds -strained homomorphs and the classification of steric strains (F-, B-, Istrains).

The non-classical ion problem, which is the topic of part 3 , has been the subject of long-standing controversy, particularly with the late Saul Winstein, and has now become a part of chemical folklore. The relationship to the boron studies is perhaps based on the tenuous recognition that a carbonium ion is isoelectronic with a borane.

Part 4 is concerned with selective reductions using hydrides or complex hydrides of boron and aluminium and the question of selectivity. Reagents such as disiamylborane are uniquely associated with Brown, not least in their nomenclature.

In part 5, which is devoted to hydroboration and essentially updates Brown's monograph on the subject of 1962 , the author is mainly concerned with boron-carbon bond-making. The term "hydroboration" is probably interpreted by the organic chemist as a combination of this process together with a subsequent boron-carbon bondmaking, usually without isolation of the boron intermediate. The value of the overall procedure lies in a combination of factors which includes mild reaction conditions, essentially quantitative yields, a high degree of selectivity and stereospecificity, and a multiplicity of similar specific cleavage reactions. Thus it is possible to convert acetylenes or olefins to numerous functional derivatives including higher homologues. Part 6 deals with organoboranes from the point of view of boron-carbon cleavage reactions. From the standpoint of the organic chemist, parts 5 and 6 thus form a continuous story.

Professor Brown is, and has been, one of the giants of chemistry of the last thirty years. He is a splendid controversialist, both verbally and in writing, and the present contribution is in this same happy tradition.

M. F. LAPPERT

\section{Structures in Cells}

The Generation of Subcellular Structures. By R. Markham, J. B. Bancroft, D. R. Davies, D. A. Hopwood and R. W. Horne. Pp, $x+372$. (NorthHolland: Amsterdam and London; Elsevier: New York, 1973.) Dfl 45; £7.

THE three-dimensional structures of subcellular biological systems and mechanisms for their biosynthesis are now elements of perhaps the most important next stage in molecular biology. The problem is ripe for attack and the timing and choice of this subject for the first John Innes Symposium (held in July 1972) could not have been more appropriate. It has been excellently organized and the individual subsections well selected, being here presented in a series of stimulating articles by leading exponents from many parts of the world.

Prefaced by a suitably general historical review of molecular genetics in the form of the sixth Bateson Memorial Lectures by W. Hayes, the proceedings of the meeting include a fairly wide collection of original reports on the structure and synthesis of organelles (usually in the form of summaries of recent advances). The range stretches from relatively simple systems such as bacterial flagella and plant viruses through larger viruses, such as $\mathrm{T}_{4}$ phage, towards bacterial spores and the more complex sophistications of ribosomes, cell walls and mitochondria. Contributors include D. Kerridge, H. R. Revel, E. Kellenberger, J. G. Atabekov, M. Nomura, R. A. Cox, A. Ryter, P. C. Fitzjames, Audrey Glauert, B. A. Afzelius and many others.

It is worth noting that all the systems considered here derive from viruses or prokaryotes, where the relatively simple structures involved are easier to study than the complexities of eukaryotes, but where the basic lessons to be learnt and the models that emerge are applicable to all types of living systems.

Perhaps the most fundamental problem in this field is the extent to which all necessary information for the correct assembly of subcellular organelles (indeed for the whole cell, for that matter) is contained in the structures of their constituent molecules. Another (slightly more restricted) way of putting it would be to ask whether the DNA or RNA genome contains all the necessary instructions for putting together the nor- mal three-dimensional structures involved. This naturally leads to two rather more specific queries. (1) How far can assembly of multimolecular complexes occur in the absence of pre-existing structure and, in cases where some sort of pre-existing structure is required, how specific must it be? (2) To what extent, in the construction of such complexes, is a sort of scaffolding necessary-in the sense of an essential structure that is not contained in the final finished organelle?

The articles in this symposium do not of course provide a complete, generalized answer to this sort of question. But they begin to indicate the sorts of ways in which answers can be given. It would be impossible to summarize any general conclusions, although the reader is left with a strong feeling that this is an area where much progress will occur rapidly during the next 10 years.

Perhaps, above all, what has emerged fairly clearly is the extent to which spontaneous assembly of relatively complex structures can occur (being often demonstrable in vitro) simply through molecules "finding each other" by interactions between complementary patterns on their surfaces. Temporary scaffolding, specific catalysis by enzymes, complex "foundation" molecules acting as a specific nidus for the association of other key molecules -if they exist (as they appear to do in certain cases)are not always necessary, although there is often an obligatory sequence in the assembly process (for example, with ribosomes) and/or a polarity in the direction of build-up, even of monomers in simple complexes such as flagellar filaments.

Having emphasized what a fascinating collection of articles is here available in an exciting field, some protest must be made about the publication itself. The offset-type process used is more tiring and difficult to read than ordinary print, the legends are not properly distinguished from the text, some tables are in type almost too small to decipher, the section headings do not stand out clearly and italics are not properly visible. The discomfort involved might be tolerable if the book were cheap.

M. R. POLLOCK

\section{Practical Concern}

Guide for Safety in the Chemical Laboratory. Second edition. (Manufacturing Chemists Association.) Pp. vi+505. (Van Nostrand Reinhold: New York and London, 1972.) £8.75.

A SMALL stretch of the imagination should inform us that the first task of the contemporary, socially concerned scientist is to make sure that neither he nor those working with him are blown up, burnt to cinders or dissolved in acid. Yet it is a matter of record 